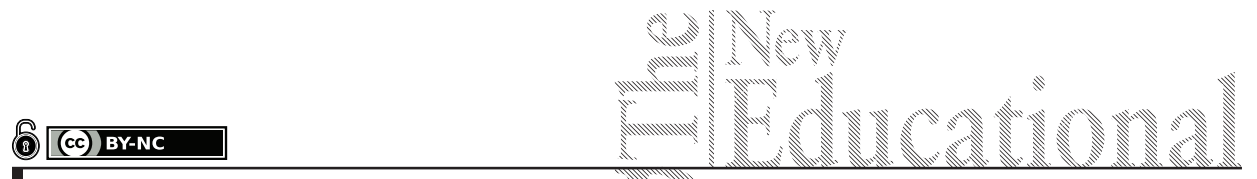

Alina V. Dulia, Tetiana L. Liakh, Tetiana G. Veretenko

Ukraine

\title{
The Problems and Needs of the Families of Antiterrorist Operation Participants: Results of In-depth Interviews
}

DOI: 10.15804/tner.2019.55.1.18

\begin{abstract}
The article explores the key issues and needs of families of participants in anti-terrorist operation (ATO). The article defines and characterizes several types of families of ATO participants, who took part in an interview. Based on in-depth interviews and further analysis, the authors identified four categories of problems of these families, e.g., psychological, financial, legal, and problems with raising children. It was determined that violations of the life of the families whose members were ATO participants were caused not only by family-specific problems but also by several other factors. Based on the identified specific problems, the authors identified the main needs of the families of the members of antiterrorist operations.
\end{abstract}

Keywords: families of participants of anti-terrorist operation (ATO), psychological problems, financial problems, problems with paperwork, problems with the upbringing of children, needs of family members of ATO participants

\section{Introduction}

The military conflict in Eastern Ukraine has caused profound changes and affected all spheres of the life of citizens, and society as a whole. This is especially true of the families of combatants, as during the stay of one family member in the ATO zone, their close relatives appeared under the influence of external and inter- 
nal stress factors that disrupt the normal life cycle and balance of the family and put their members in a vulnerable position. Thus, the families of ATO participants need social support and assistance.

The problem of social support for the families of ATO participants is becoming increasingly urgent today.

\section{Research problem and Focus}

A number of foreign social scientists (J. Judy, J. Cooper, M. Chartrand, D. Frank, T. Shope, J. Mancini) has studied the consequences of the stay of a family member in a war zone, noting that family members of combatants are in a stressful situation during the stay of one of the family member in the war zone and are exposed to negative impacts.

Several foreign researchers (C. Taylor, M. Ross, J. Wood, G. Harb, K. Lynch, D. Rubin, 2015) argue that both children and adults who are the family members of combatants have problems during the absence of their fathers. Children adopt more risky behavior, become more aggressive, disobedient, and early begin to assert themselves. The researchers also noted that children are at high risk even after the returning of their fathers, which is indicated by the increase in stress in families during the stay of combatants in the war zone and after their return home.

This is also the opinion of another foreign researcher, J. Buehrle (2014), who notes that school-age children whose parents are in the war zone are more likely to of develop behavioral problems. In addition to the research, the author argues that a family member's stay in the area of military conflict has a negative impact on the career of the other the spouse, because they are in constant stress, anxiety, and are forced to fulfil all the requirements of the family.

According to other studies (K. Iverson, D. Vogt, M. Dichter, S. Lou, 2015), the wives of war veterans exposed to sexual violence from men have post-traumatic stress disorder, depression and other mental health disorders. There are other studies of post-traumatic stress disorder in individuals exposed to military trauma (I. Reuveni, O. Bonne, R. Giesser, T. Shragai, G. Lazarovits, , M. Isserles, S. Schreiber, A. Bick, N. Levin, 2016).

In their study, K. Maguire and E. Parcell (2015) examine the concept of overcoming paradoxes in military families during deployment military actions. They identified six paradoxical combinations of individual stress factors and strategies to overcome them for wives whose husbands were at war. The majority of foreign researchers indicate that members of families of servicemen who take part in fighting could have problems associated with psychological health, i.e., post-traumatic stress disorder, depression, constant stress and undue anxiety and fear. 


\section{Research Methodology}

In the study, we conducted a series of in-depth interviews with members of families of ATO participants. The purpose of the interviews was to identify the respondents' major problems and needs, assess the quality of services provided by state and public organizations, and proposals of the members of the families of ATO participants about the provision of social support. The respondents were invited to participate in the interviews through ads posted on social networks as well as through personal letters to members of the families of the ATO participants, and through verbal invitations.

The research interviews with open questions explored available social support to this category of families. The list of issues to explore was as follows: the number and quality of applications of members of families of ATO participants to the state and public organizations; the quality of services received, and level of satisfaction of needs, in particular, social support; requests of members of families of ATO participants for special social support.

According to the methodology of grounded theory, encoding occurred simultaneously with data collection. Initial encoding was open and close to the text, this means that the codes were designed to reflect the actions, intentions and meanings of the respondents, often using their own words. Further interview encoding was the current use of comparative analysis, which made it possible to identify such codes into categories. The answers were carefully analyzed and some minor changes made.

After initial isolation of the categories, it modified the process of attracting participants. To provide the most diverse selection, participants were selected according to their ability to explain the specific issues, which had been identified in the previous study. This approach is called "theoretical sampling" (Glaser, B.G., Strauss, A.L., 2012) and it allows for formulating specific questions for interviews.

\section{Research Results}

In-depth interviews were held with 47 members of families of ATO participants in three regions of Ukraine: Kyiv, Chernihiv, Zhytomyr region.

The interviews began with questions of personal data. The results of this survey made it possible to divide the respondents into four groups according to the types of families of participants of the antiterrorist operation, which are the following: 
family members of ATO where one of its members is in the combat zone now (55.3\%); family members of the antiterrorist operation where one of its members returned from the combat zone (25.5\%); families where one member is a disabled veteran (12.8\%); and families of deceased members of ATO (6.4\%).

During the interview, we determined that despite the fact that the majority of the respondents are members of families of ATO participants where one of its members is in the zone of hostilities, the problems they have now are caused by the stay of the family member in the war, but the message that he became the participant in ATO led to stress, misunderstandings and conflicts in the family. 93.6\% of the respondents said that when they got the news that their relatives would become involved in the fighting, they felt anxiety, worry and fear and had tears in their eyes. They did not want to accept this information and let their relatives go to war; they felt anger with the country because it endangered the life and health of its citizens. However, $46.8 \%$ of the respondents took this situation as necessary and inevitable. To the question "What was the reaction of all family members to the news that one of its members would become a participant in ATO?" the first respondent said: "When the war started we knew that my husband would take part because he is a military person and a true patriot. That's why I could not forbid him to protect the Homeland". The second respondent said: "In view of the military and political situation in Ukraine, we took this message as calmly as possible".

The situation of the family members of ATO participants who went to war as volunteers was different, so according to this, we divided the respondents into two groups, which were "for" and "against. About $19.1 \%$ of the respondents of the first group admitted that it was difficult to make a decision their husband/son/ daughter, but the family did not let them down, supported them and provided with all necessary things, at the moment of making a decision. The same question was answered by the third respondent in the following way: "My husband had to go to the war as a volunteer because our family has financial difficulties". $34 \%$ of the respondents were totally against their loved one's volunteering to fight. The fourth respondent said: "I was stressed... The whole family did not understand why he wanted to leave us and exposed himself to danger". Another respondent stated: "All members of the family were strongly opposed because my husband had problems with his health". The results of the responses of the second group indicate that the family members were trying to put pressure on the future ATO participant and to prevent his decision, which usually leads to misunderstandings, disputes and conflicts in the family, which causes disintegration of the family even before the departure of one of its members to the war zone. 
Our research shows that the majority of the members of the families of the ATO participants (57.4\%) may not see their loved ones who are in the military conflict zone for almost a year. Furthermore, the responsibility for the functioning of the family and raising children is passed on to the woman, who is also in psychological stress. Consequently, we can say that the life of the members of the families of ATO participants changes dramatically when their loved ones become combatants. Adult members of such families feel that they have lost their own lives, they shift all responsibility to their family. All the duties which the women shared with their husbands now have to be done by themselves, so it is difficult for them physically and emotionally to adjust to the new changes and perform all the household chores, to educate minor children, to care about the sick parents and get a job.

According to the abovementioned, we can conclude that all the interviewed family members of the ATO participants were in disturbed emotional state. The reason for such breach is a traumatic event when one of the family members stays in a combat zone. The impact of a traumatic event upsets the balance in the family and puts all family members in a vulnerable position, which is manifested in increased tension, anxiety and emotions. The family members who stay at home without emotional contact and support from the close person become mentally burnt out.

Therefore, almost all the respondents (95.7\%) said that during the stay of one of the family members in the combat zone they lived in constant nervous and psychological tension, stress, fear, they felt anxiety and constantly anticipated the news that could ruin their lives. $44.7 \%$ of the respondents observed psychological unpreparedness for independent problem-solving, lack of self-confidence and feeling of hopelessness. The feeling of psychological exhaustion, nervousness and insomnia increases the foregoing.

In the study, we found that the children of the families of ATO participants are also exposed to traumatic events related to the participation of the father in fighting actions. The need for emotional intimacy between father and children is not fully satisfied, also we could see the lack of symptoms of positive feelings towards themselves and towards others, lack of tenderness, gentleness, parental warmth and love. The child in such a family periodically or continuously lives in conditions of incomplete and blocked family communication.

$76.6 \%$ of the children of the families of ATO participants observed a sense of alarm for the life of the father; they missed him and were waiting for meeting with him, but at the same time, felt abandoned and became angry and aggressive.

The obtained results showed that the children of the families of the ATO participants no longer perceived adults as guarantors of their own safety, losing 
the emotional comfort that the family traditionally had provided. This is because children often see adult family members helpless and unprotected.

In the course of the study, we determined that when one family member is again in the zone of the anti-terrorist operation, all of the above problems only intensify.

About $42.5 \%$ of the respondents felt that each time it was harder and harder to receive the information about their relatives starting to fight. It aggravated resentment, betrayal because they left them again even if they had promised not to go. This sensation leads to misunderstandings and conflicts.

Answering the question "What changes have occurred in your and other family members' lives after one of the family members went to the ATO zone again?", the first respondent said: "The children and I felt hurt that he lied to us, did not tell the truth, promised not to go to war, but left us again"; the second respondent said: "I was completely mortified, I didn't want anything. I tried to lose myself in work, in the family, but in the evening when I stayed alone, I could not hold back the tears. It was emotionally hard for me" (at these words, tears).

We noted that the strength and patience of the wives of the ATO participants decreased with each passing day waiting for their husbands; there was a feeling of passivity, mood swings and depression. Violation of the psycho-emotional state, constant feelings of anger, anxiety and depression over a long period of time adversely affect health and lead to its deterioration. The study gave us the opportunity to identify the actual problems of the families of the participants in anti-terrorist operations, which we divided into four groups (Picture 1):

1) psychological problems (95.7\%): increased stress, concern, anxiety, fear, anxiety (95.7\%); loneliness (27.7\%); deficit of symptoms of positive feelings (34.0\%); limitations in interpersonal and intra-family interaction (42.5\%); psychological exhaustion (48.9\%); anger, wrath, resentment (29.8\%);

2) material problems $(80.9 \%)$ : the inability and fatigue from independent resolving of everyday issues with a family member who stayed home (68.0\%); unemployment of one of the family members that stayed home $(12.8 \%)$; dependence of the wages of the participants in ATO and the delay of his wages (36.2\%); the cost of treatment and rehabilitation of the anti-terrorist operation, who was wounded, and sick parents, children (19.1\%); lack of one's own housing (17.0\%);

3) legal problems (paperwork) (61.7\%): obtaining the legal status of "combatant", "war veteran" and "member of the family of the deceased" (44.7\%); getting financial assistance (40.4\%); land (40.4\%); housing and monetary compensation for housing (38,. \%); free treatment and rehabilitation (34.0\%); rehabilitation and recreation of all family members (57.4\%); 
4) problems with child-rearing (53.2\%): problems with learning at school (31.9\%); disobedience, no accountability, irresponsibility and the development of early autonomy (23.4\%); manifestations of aggressiveness and protest $(19.1 \%)$.

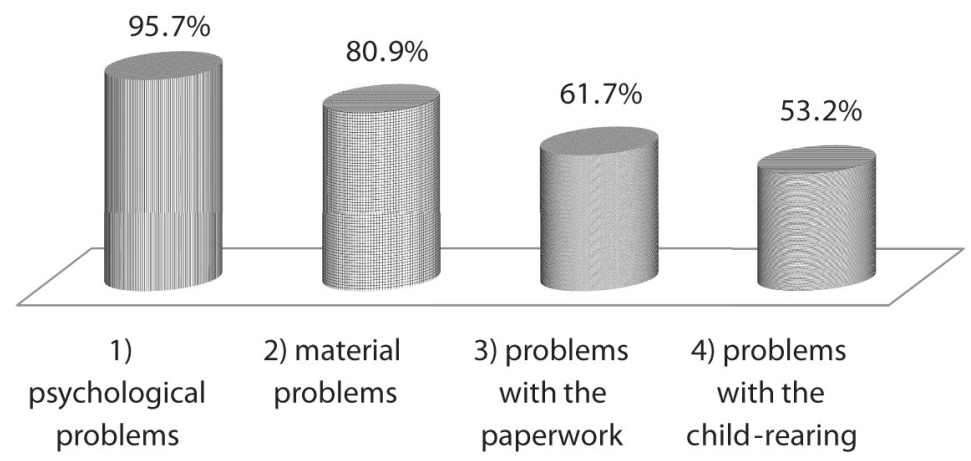

Picture 1. Actual problems of family members of ATO participants

We found that an important problem of these families is the fear for the safety of the family member who is a member of the antiterrorist operation, causing anxiety, loneliness, and sadness among all the family members, both adults and children.

In the study, we determined that ATO participants come home with revaluated life values and changes in the typical responses of the individual. Actually, life for the family of ATO participants has also changed because of the new experience of independent life, new habits, acquaintances, and friends. That is why the members of the family and the combatants may feel that they know little about each other, so it is emotionally difficult to establish new interpersonal and intra-family interactions. $31.9 \%$ of the respondents said that one of the main problems after returning home is difficulties at the household level. It is difficult for the combatants to return to routine, and the family members, who had independently solved all the problems at home wanted to quickly pass them on because they were emotionally and physically depleted themselves.

Despite all the hardships and difficulties after returning of a family member home, almost all the respondents (38.3\%) said that they were happy their loved ones were back alive.

In the study, we determined that $59.6 \%$ of the respondents' have some knowledge about the services to which they are entitled, although the respondents' awareness of the spectrum of possible services is fragmentary, they know a few 
of the types of services that they are entitled to: housing and monetary compensation for housing; provision of land; benefits for housing and utilities and fuel cost; free treatment and rehabilitation of combatants; free meals in primary and secondary schools; free training in higher education institutions; rehabilitation and recreation of children, etc. $40.4 \%$ of the respondents do not know about their rights and entitlements and do not know where to get help, indicating a low level of awareness of the members of the families of ATO participants on this issue.

The obtained results give us grounds to assert that at the state level educational work is still not carried out with the aim of informing the public about the types of social support and social services to eligible members of families of participants of the antiterrorist operation.

$72.3 \%$ of the respondents often sought social support in such state and public organizations like "Ukrainian Association of Combatants", "Kyiv city Union of Veterans of ATO", Center for Family and Children Support, Desnyanskiy District in Kyiv, etc.

In the course of the empirical research, we determined that the members of the families of ATO participants often approach the state and non-governmental organizations for the following types of social support:

- legal support (31.9\%), including obtaining assistance and various social benefits, such as financial assistance, land plot, recognition of the status of "combatant" and "member of the family of the deceased";

- financial support (61.7\%), including obtaining financial assistance, financial assistance for burial, medical treatment and rehabilitation, benefits for housing and communal services, obtaining the land, the purchase of a car; the provision of housing and housing improvement;

- socio-pedagogical support (63.8\%), including free access to higher education, visits to cultural and entertainment events, leisure for children and adult family members;

- psychological support (51.1\%), including assessment of the emotional state, psychological consultations, psychological therapy connected to post-traumatic stress disorder, group therapy and self-support groups, psychological and spiritual assistance (cf., Picture 2.).

The results suggest that the family members of ATO participants just need the aforementioned types of social support.

The quality of the provision of social support for the family members of ATO participants is below the average. These results indicate that professionals who provide social support do not know the peculiarities of work with this category of clients and do not have special training and, therefore, there is a need for training 


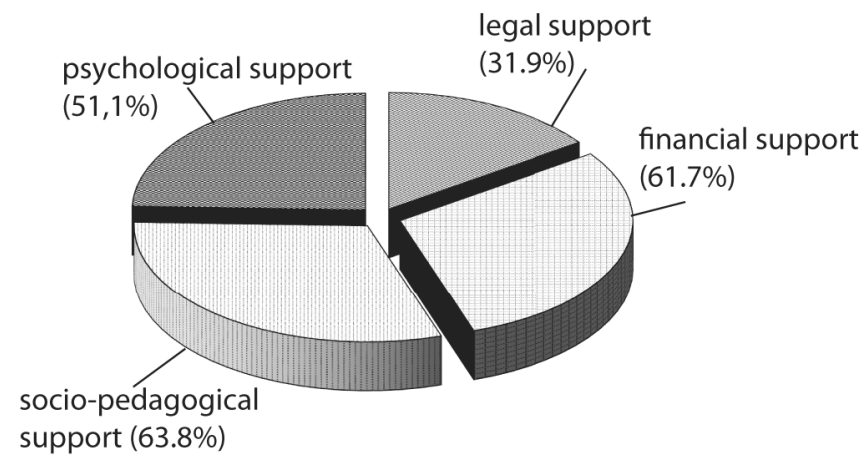

Picture 2. Types of social support that members of families of ATO participants often seek in state and public organizations

in the area of social support for the ATO participants and their families. According to the results, we can say that one of the basic needs of the family members of ATO participants is obtaining high quality and skilled social support.

Based on the results of our studies, we have identified the basic needs of family members of ATO participants. The summarized results of the basic needs in social support are presented in Picture 3.

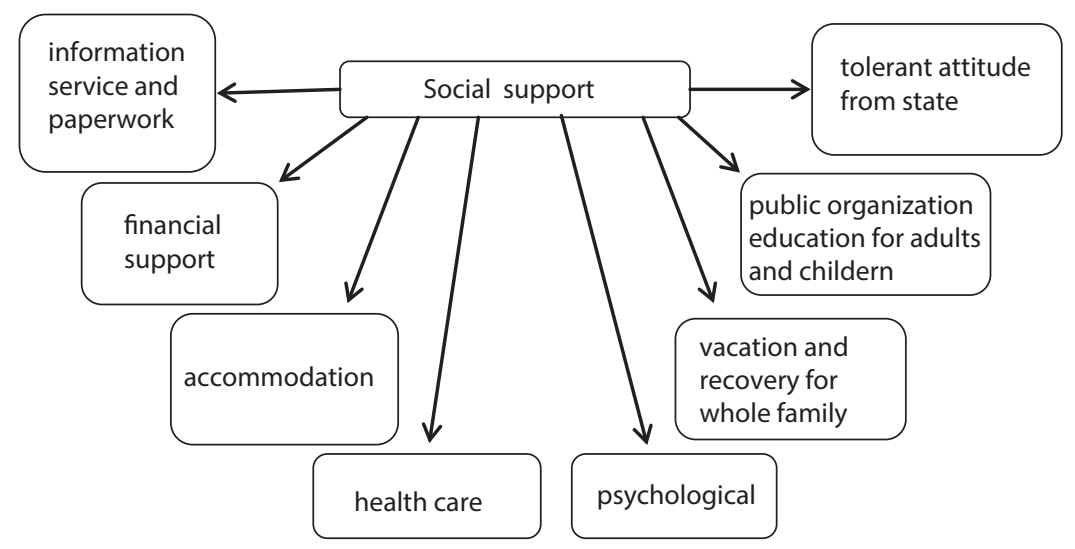

Picture 3 The needs of members of families of ATO participants in social support 


\section{Discussion and conclusion}

The obtained results of the in-depth interviews indicate that violations of the life of the families of combatants are caused not only by specific family problems but also a number of other factors: e.g., anxiety over the life of a family member who is in the zone of anti-terrorist operation; uncertainty about the future; uncertainty of life prospects; isolation of the family; the weakening of their adaptability in social relationships; the inability of families to resolve problems; ATO participants' lack of participation in family life and parenting; problems with education and upbringing of children; fatigue; material instability; bad housing; health problems of family members.

All the respondents stressed the importance of developing an effective program of social support for the families of ATO participants. Their planned criteria and indicators of the quality of services allowed us to develop such a program and implement it in practice in the use of public organization "Kyiv City Union of Veterans of the ATO". A comprehensive program of social support of the families of ATO participants is based on the specific problems and needs of family members; capacity of the institution that provides such support; provision of legal, material, psychological and socio-pedagogical support of highly qualified specialists

\section{Acknowledgements}

The study was conducted in the framework of the scientific themes of the Institute of Human Sciences, Boris Grinchenko Kiev University: "Personality in conditions of social transformations of modern Ukraine", registration number: 0116U002960, over the period 5.2016-5.2021.

\section{References}

Buehrle, J. (2014). «Us» as the United States: Sparking Community-based Solutions for Supporting Military-connected Children and Their Families. Children \& Schools, 36(1), 60-63. doi:10.1093/cs/cdt045

Brickell, M., Russell, M., \& Smith, R. (2015). The Effectiveness of Evidence-Based Treatments in Treatment of Active Military Personnel and Their Families. Journal of EMDR Practice and Research, 9(11), 198-208. doi: https://doi.org/10.1891/1933-3196.9.4.198 Hoge, C.W., Ivany, C.G., Brusher, E.A., Brown M.D., Shero, J.C., Adler, A.B., ... Orman, D.T. (2015) Transformation of Mental Health Care for U.S. Soldiers and Families During the Iraq and Afghanistan Wars: Where Science and Politics Intersect. American Journal of Psychiatry, 173(4), 334-343. doi: http://dx.doi.org/10.1176/appi.ajp.2015.15040553 
Iverson, K.M., Vogt, D., Dichter, M.E., Carpenter, S.L., Kimerling, R., Street, A.E., ... Gerber, M.R. (2015). Intimate Partner Violence and Current Mental Health Needs Among Female Veterans. Journal of the American Board of Family Medicine, 28, 772-776. doi:10.3122/jabfm.2015.06.150154

Katheryn C. Maguire, \& Erin Sahlstein Parcell (2015). Communication and the Coping Paradox: The Case of Army Spouses and Wartime Deployment. Southern Communication Journal, 80(5), 365-376. doi:10.1080/1041794X.2015.1081973

Reuveni, I., Bonne, O., Giesser, R., Shragai, T., Lazarovits, G., Isserles, M., ... Levin, N. (2016). Anatomical and functional connectivity in the default mode network of post-traumatic stress disorder patients after civilian and military-related trauma. Human Brain Mapping, 37, 589-599. doi:10.1002/hbm.23051

Taylor, C.M., Ross, M.E., Wood, J.N., Griffis, H.M., Harb, G.C., Mi, L., ... Rubin, D.M. (2015). Differential Child Maltreatment Risk Across Deployment Periods of US Army Soldiers. American Journal of Public Health, 106(1), 153-158, 1-6. doi:10.2105/ajph.2015.302874 Glaser, B.G. \& Strauss, A.L. (2012). The Discovery of Grounded Theory: Strategies for Qualitative Research. New Brunswick \& London. Aldine Transaction. 